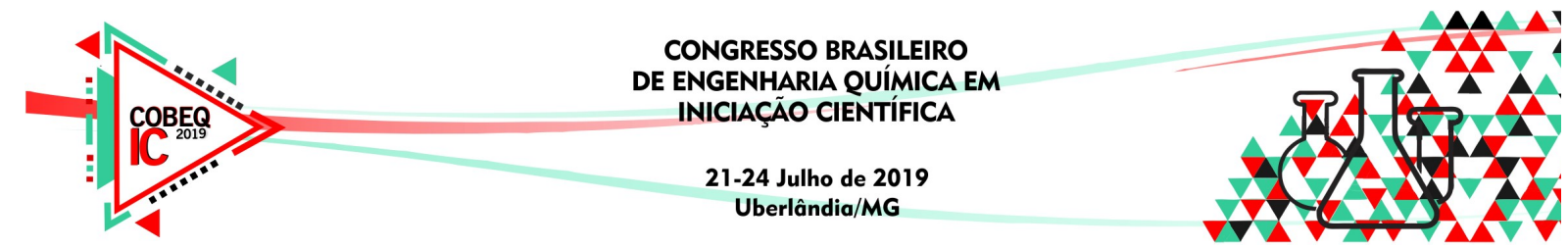

\title{
DISCRIMINAÇÃO DE MODELOS CINÉTICOS APLICADOS À PRODUÇÃO DE BIOMASSA DE Herbaspirillum seropedicae EM BIORREATOR EM BATELADA UTILIZANDO O SOFTWARE EMSO
}

\author{
Giovane Massena Petruccelli ${ }^{1}$, Luiz Augusto da Cruz Meleiro ${ }^{2}$ e Maurício Cordeiro Mancini ${ }^{3}$ \\ ${ }^{1}$ Bolsista PIBIC/CNPq/UFRRJ; \\ ${ }^{2}$ Universidade Federal Rural do Rio de Janeiro, Departamento de Engenharia Química; \\ ${ }^{3}$ Orientador - Universidade Federal Rural do Rio de Janeiro, \\ Departamento de Engenharia Química; \\ E-mail para contato: giovanepetruccelli@gmail.com; mancinimc@gmail.com;
}

RESUMO - O presente trabalho objetivou o desenvolvimento de programas simuladores e rotinas de estimativa não-linear de parâmetros utilizando o software livre EMSO (Environment for Modeling, Simulation and Optimization) visando a simulação e discriminação de modelos cinéticos mais adequados para a produção da bactéria Herbaspirillum seropedicae em biorreatores em batelada. Este microrganismo se mostra como um potencial inoculante no mercado agrícola por apresentar a capacidade de fixar o nitrogênio atmosférico, além de produzir fitohormônios promotores de crescimento em plantas. Os dados experimentais estão disponíveis na literatura e levam em consideração três meios de cultura distintos, sendo otimizações derivadas do meio DYGS (Dextrose Yeast Glucose Sucrose). Os programas simuladores, desenvolvidos em EMSO, possibilitaram a avaliação da cinética e a determinação dos parâmetros dos modelos de Monod, de Moser, de Contois \& Fujimoto e de Andrews. Após a determinação dos parâmetros, por meio da ferramenta Estimation, disponível no EMSO, foi possível proceder a discriminação dos modelos cinéticos mais adequados para cada meio de cultura considerado, tomando como critérios de discriminação os coeficientes de determinação $\left(\mathrm{R}^{2}\right)$ e os desvios relativos médios (DRM). Para os três meios analisados, o modelo de Contois \& Fujimoto apresentou os melhores resultados de $\mathrm{DRM}$ e $\mathrm{R}^{2}$, ou seja, menores desvios relativos médios, variando de $13 \%$ a $20 \%$ para biomassa e $4 \%$ a $9 \%$ para o substrato, bem como os maiores coeficientes de correlação, todos acima de 0,97. Além da discriminação dos modelos, foi possível observar, por meio da estimativa de parâmetros, a existência de valores de coeficiente de manutenção da célula negativos. Com base nesta constatação, é possível considerar a hipótese de que este microrganismo tem a capacidade de armazenar energia e utilizá-la para a sobrevivência. 


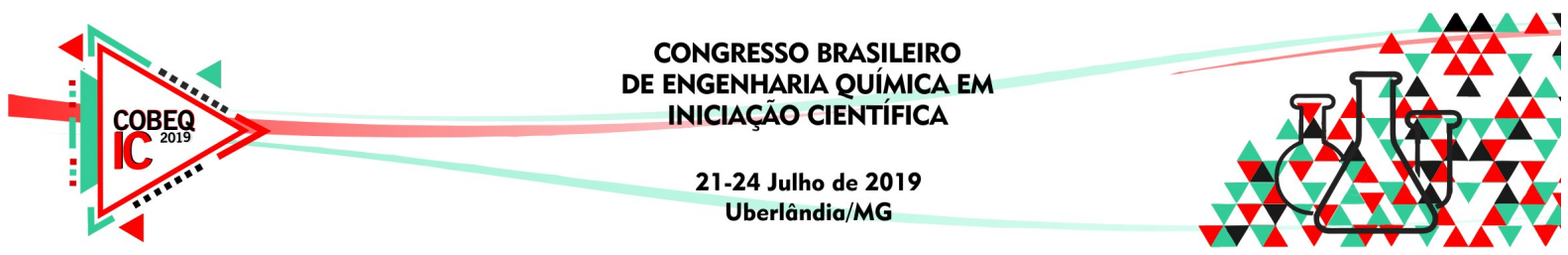

\section{INTRODUÇÃO}

O Brasil é uma das principais potências agrícolas mundiais e permanece em contínua expansão. O país se mantém como o terceiro maior exportador de grãos, tendo como seus principais produtos de exportação arroz, milho e soja. (CONAB, 2013).

Entretanto, para que seja possível atender à alta demanda, é necessário que haja o desenvolvimento das culturas em sua máxima capacidade. Para isso, diversos nutrientes são exigidos e a maior parte dos solos brasileiros não é capaz fornecer todos os que são necessários para o desenvolvimento da planta, sendo imprescindível a correção do solo com adubos e fertilizantes. Entre os principais nutrientes encontra-se o nitrogênio. (FERREIRA et al., 2010)

Esse nutriente encontra-se em abundância em nossa atmosfera, no entanto, nesta forma, não é diretamente assimilado pelo solo. Tendo isso em vista, o método Haber-Bosch foi criado com o intuito de fixar o nitrogênio atmosférico transformando-o em amoniacal. No entanto, é um processo desvantajoso economicamente e ambientalmente, uma vez que há possibilidades de contaminação de lençóis freáticos e degradação do solo (SCHEIDT, 2015).

Uma potencial alternativa é a utilização de bactérias fixadoras de nitrogênio no solo. São chamadas de diazotróficas as bactérias que possuem a capacidade de quebrar as ligações do nitrogênio atmosférico e, juntamente com o hidrogênio, transformá-lo em nitrogênio amoniacal, sendo assimilável pela planta. Este processo é chamado de fixação biológica de nitrogênio (SCHEIDT, 2015).

\subsection{O Microrganismo Herbaspirillum seropedicae}

O microrganismo foco da pesquisa, Herbaspirillum seropedicae, é diazotrófico endofítico, isto é, permanece grande parte do seu ciclo de vida nas raízes da planta hospedeira fornecendo os nutrientes de forma direta. Além disso, verificou-se que este gênero possui mecanismos capazes de potencializar o crescimento de plantas através da produção de fitohormônios promotores do crescimento, sendo denominado uma rizobactéria promotora de crescimento de plantas (RPCP). (BALDANI et al., 1986).

O mais ativo fitohormônio promotor de crescimento é o composto indólico ácido indol-3-acético (AIA), que proporciona diversos benefícios para planta, tais como o favorecimento na formação celular, iniciação das raízes laterais, na formação de gemas florais e no desenvolvimento do fruto. (BASTIÁN et al., 1998)

Tendo em vista as características dessa bactéria, é coerente considerar a possibilidade da mesma ser utilizada como um inoculante. Um inoculante é definido como todo produto, a base de microrganismos, capaz de favorecer de alguma forma o desenvolvimento de plantas ou um biofertilizante, composto por microrganismos vivos, que possuem como característica a capacidade de auxiliar de forma direta ou indireta o crescimento vegetal por meio de diferentes mecanismos, (FERREIRA et al,, 2010; SILVA, 2009; REIS et, al,, 2009).

Para que seja utilizado como um inoculante é importante que haja um estudo da cinética do microrganismo em diversas condições de operação, para que tenha conhecimento mais preciso da evolução do crescimento celular, consumo de substrato, formação de produtos e outros possíveis parâmetros que estejam relacionados ao desenvolvimento celular em cada processo. 


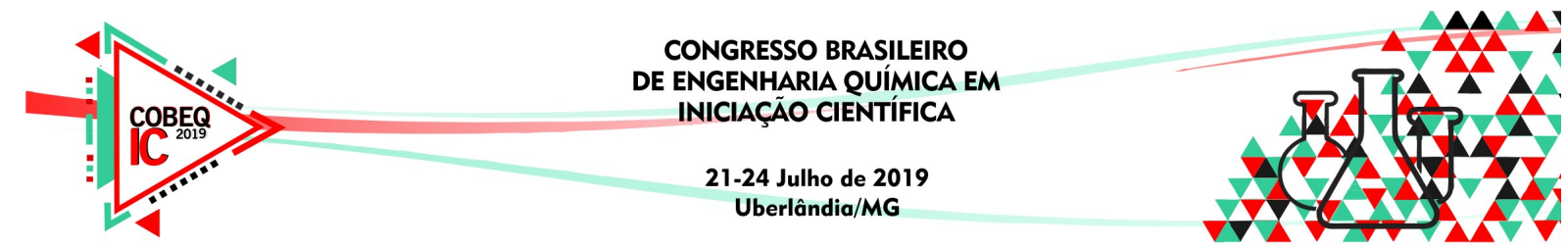

Para que o estudo cinético fosse possível, fez-se necessária a utilização de um software capaz de simular os dados experimentais obtidos na literatura, A plataforma utilizada foi o software EMSO. Esta ferramenta atual é gratuita possui uma interface de fácil entendimento e programação simples.

\subsection{O Software Livre EMSO}

Na plataforma EMSO, é possível a criação de três tipos de estruturas de programação para a descrição do processo alvo: "model", que é a descrição matemática do dispositivo ("device") utilizado no processo; "devices", que são os instrumentos utilizados no processo, como tanques e/ou reatores; e, por fim, o "flowsheet", que é o fluxograma do processo, representando o conjunto de dispositivos com os modelos anexados neles (SOARES, 2007).

O comando "Estimation" permite realizar estimativa de parâmetros dos modelos introduzidos no programa simulador criado previamente. Esta ferramenta realiza este processo com base no método dos mínimos quadrados já incorporado no software, sendo necessário o estabelecimento de uma faixa de busca. Para modelos cinéticos com muitos mínimos e máximos relativos, é necessário adotar faixas mais estreitas; já em modelos com mínimos e máximos relativos mais espaçados, é possível inserir faixas de busca mais amplas no programa. Após o fim do processo de estimativa de parâmetros, o programa fornece valores de $\mathrm{R}^{2}$ para o modelo e quantifica a significância dos parâmetros (SOARES, 2007).

Com o auxílio das utilidades oferecidas pelo EMSO, é possível obter métodos de comparação de maneira simples, mais rápidos e mais precisos que os meios convencionais. Mecanismos como a geração de gráficos, análises estatísticas e a forma simples e clara de explicitar dados, são princípios muito úteis para contemplar a finalidade didática deste trabalho, que visa à disseminação desta plataforma de simulação e modelagem entre estudantes de graduação e pós-graduação. (SOARES, 2007).

Tendo em vista todas as funcionalidades do software e a necessidade de um meio de programação que facilite o entendimento do comportamento da célula, o presente trabalho objetivou o estudo cinético da Herbaspirillum Seropedicae por meio de discriminação de modelos presentes na literatura com o auxílio do EMSO.

\section{MATERIAIS E MÉTODOS}

\subsection{Dados Experimentais}

Os dados experimentais utilizados neste trabalho foram apresentados em trabalhos disponíveis na literatura, originados do mesmo grupo e projetos desta pesquisa, e levaram em conta a avaliação do crescimento de Herbaspirillum seropedicae em três meios de cultura distintos.

Os meios de cultura utilizados têm como base de formação o meio DYGS (RODRIGUES NETO et al,, 1986), capaz de proporcionar aos microrganismos um crescimento acelerado, pois fornece fontes de carbono, nitrogênio e outros nutrientes, sendo considerado um meio rico para favorecer o crescimento máximo de bactérias em um tempo de 

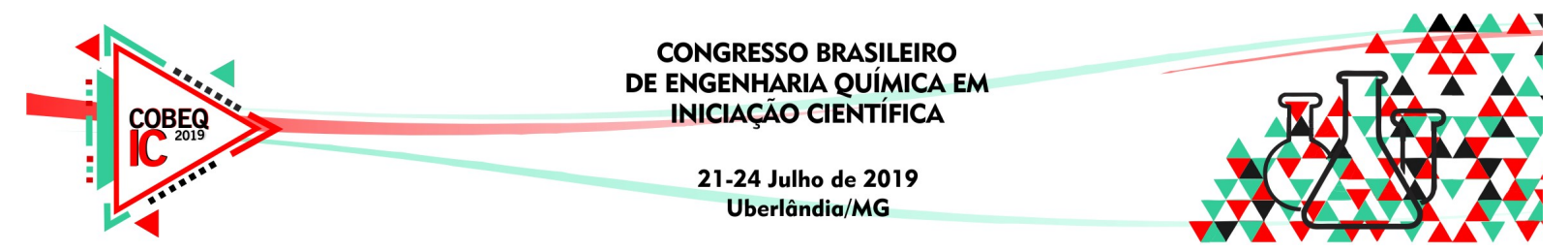

fermentação menor. Ele tem em sua composição os seguintes compostos: Glicose, ácido málico, peptona bacteriológica, extrato de levedura, ácido glutâmico, $\mathrm{K}_{2} \mathrm{HPO}_{4} \mathrm{e}$ $\mathrm{MgSO}_{4}, 7 \mathrm{H}_{2} \mathrm{O}$.

A composição dos três meios utilizados, descritos na Tabela 1, foram otimizados por Sheidt (2015) e este presente trabalho utilizou dos resultados experimentais provenientes do mesmo.

Tabela 1: Composição em $\mathrm{g} / \mathrm{L}$ dos meios de cultura utilizados na pesquisa,

\begin{tabular}{|l|c|c|c|}
\hline & Meio 1 & Meio 2 & Meio 3 \\
\hline Composto & \multicolumn{3}{|c|}{ Concentração (g/L) } \\
\hline Glicerol & 5,5 & 5,5 & 8,0 \\
\hline Peptona bact.. & 1,5 & 0,0 & 0,0 \\
\hline Extrato de levedura & 2,0 & 2,8 & 4,0 \\
\hline $\mathrm{K}_{2} \mathrm{HPO}_{4}$ & 0,5 & 0,5 & 0,5 \\
\hline $\mathrm{MgSO}_{4} .7 \mathrm{H}_{2} \mathrm{O}$ & 0,5 & 0,5 & 0,5 \\
\hline
\end{tabular}

O aumento das concentrações de glicerol e extrato de levedura no meio de cultura otimizado, busca reduzir as limitações causadas pela diminuição dos componentes do meio de cultura.

\subsection{Modelos Cinéticos}

Para que fosse possível a descrição do comportamento cinético da bactéria nos meios experimentados, levou-se em consideração apenas a presença do substrato e da célula no reator. As equações 1 e 2 definem as cinéticas utilizadas para descrever, respectivamente, o crescimento de célula e o consumo de substrato,onde $\mu_{\mathrm{x}}, \mathrm{em} \mathrm{h}^{-1}$, é a velocidade específica de crescimento da célula, $\mu_{\mathrm{s}}$, em $\mathrm{h}^{-1}$, a velocidade específica de consumo de substrato, e $\mathrm{C}_{\mathrm{x}}, \mathrm{em}$ $\mathrm{g} / \mathrm{L}$, a concentração de célula no meio. Na equação 3 , é possível observar o perfil de taxa específica para o consumo do substrato, sendo os parâmetros $\mathrm{Y}_{\mathrm{x} / \mathrm{s}}, \mathrm{em} \mathrm{g}$ de célula/g de substrato, o fator de conversão de célula em biomassa, e ms, em g de substrato. $\mathrm{h}^{-1} / \mathrm{g}$ de célula, o coeficiente de manutenção da célula.

$$
\begin{aligned}
& \frac{d C_{x}}{d t}=\mu_{x} C_{x} \\
& \frac{d C_{s}}{d t}=-\mu_{s} C_{x} \\
& \mu_{s}=\frac{\mu_{x}}{Y_{x / s}}+m s
\end{aligned}
$$

Para descrever a taxa de crescimento da células foram utilizados os seguintes modelos: Monod (1949), o mais simples, levando em consideração a presença de um substrato limitante; Moser (1958) e Contois \& Fujimoto (1959), também levam em consideração apenas um substrato limitante; e Andrews (1968), que descreve o crescimento em um único substrato limitante e inibidor. Estes modelos matemáticos têm como parâmetros, com 


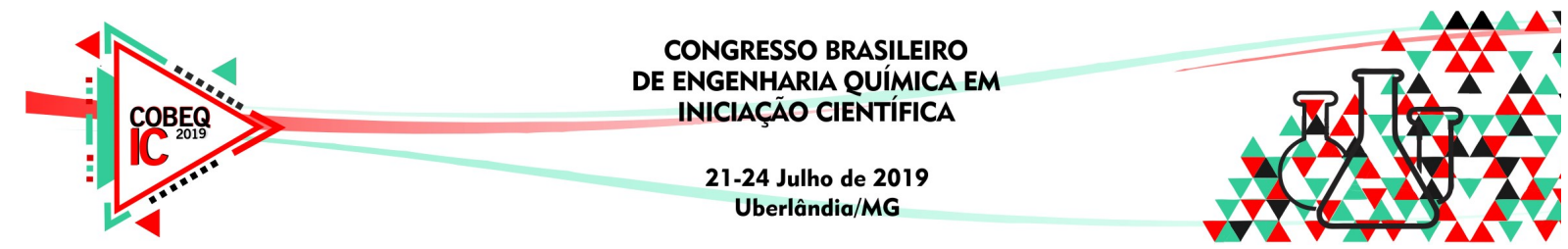

significados físico-químicos, a velocidade específica máxima $\left(\mu_{\mathrm{m}}\right)$ em $\mathrm{h}^{-1}$; a limitação causada pelo substrato $\left(K_{S}\right)$ em g/L; e a inibição proveniente do substrato $\left(K_{i}\right)$ em g/L; sendo relacionados com a concentração de substrato no meio $(\mathrm{Cs})$ em g/L. O parâmetro n, no modelo de Moser, não possui significado físico-químicos, sendo considerado apenas um parâmetro de ajuste.

Os modelos de Monod, Moser, Andrews e Contois \& Fujimoto estão apresentados, respectivamente, nas equações 4, 5, 6 e 7 .

$$
\begin{aligned}
& \mu_{x}=\frac{\mu_{m} C_{s}}{K_{s}+C_{s}} \\
& \mu_{x}=\frac{\mu_{m} C_{s}^{n}}{K_{s}^{n}+C_{s}^{n}} \\
& \mu_{x}=\frac{\mu_{m} C_{s}}{K_{s} C_{x}+C_{s}} \\
& \mu_{x}=\frac{\mu_{m} C_{s}}{K_{s}+C_{s}+C_{s}^{2} / K_{i}}
\end{aligned}
$$

\subsection{Rotina de Simulação e Estimativa de Parâmetros}

Para a simulação dos dados experimentais, foi selecionado o flowsheet como estrutura de programação para a criação de uma rotina de simulação, tendo em vista que, na metodologia adotada, foi necessária apenas a descrição de um equipamento, o biorreator, com um modelo para cada programa.

Por apresentar uma linguagem muito simples, para que o programa fosse apto para a simulação, foi necessário apenas indicar os parâmetros, variáveis, condições de operação, equações cinéticas e as opções de tempo de processo e amostragem. A estrutura do programa está exemplificada na figura 1 .

Figura 1: Fragmento de programa do EMSO descrevendo a rotina de simulação do biorreator, usando o modelo de Monod.

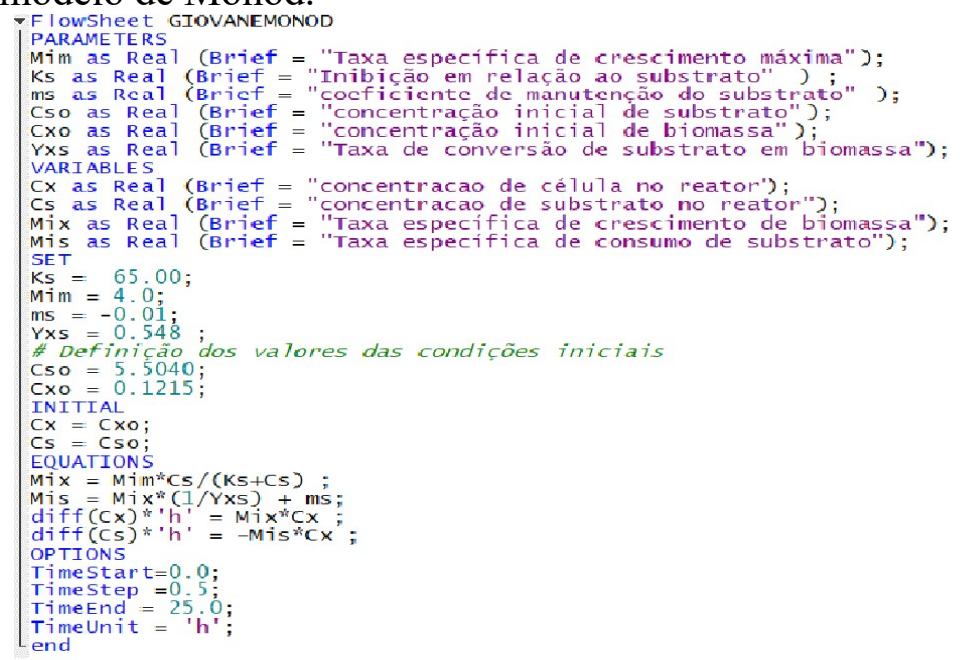




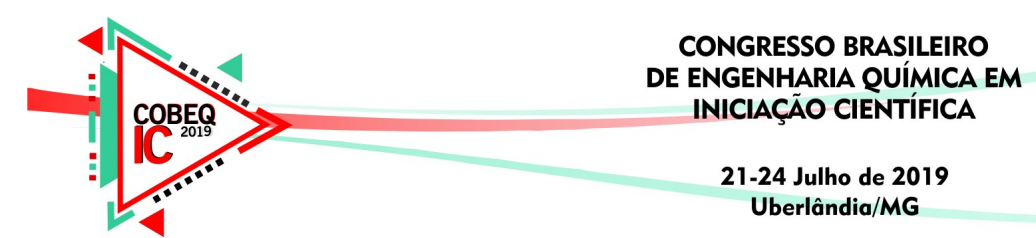

A fim de estimar os valores de parâmetros que melhor ajustam os resultados simulados às curvas experimentais, foi utilizado o comando Estimation, disponível na plataforma EMSO.

O procedimento de estimativa de parâmetros requer a indicação do arquivo com os resultados experimentais do processo de fermentação da Herbaspirillum seropedicae no biorreator, assim como da faixa de busca, o flowsheet operacional e as opções estatísticas. $\mathrm{O}$ comando pode ser observado no exemplo exposto na figura 2.

Figura 2: Fragmento de programa do EMSO descrevendo a rotina de estimativa de parâmetros, usando o modelo de Monod.

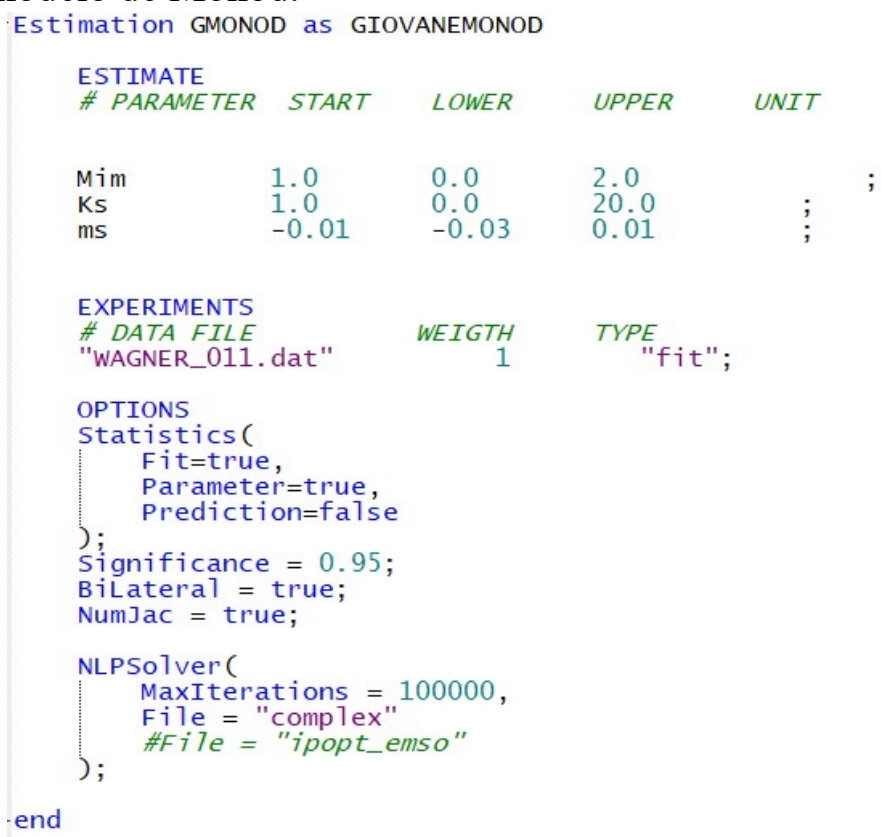

\section{RESULTADOS}

Foram determinados os valores dos parâmetros para cada modelo e cada meio com o auxílio do comando Estimation. Os resultados são apresentados na tabela 2.

Tabela 2: Valores de parâmetros estimados em cada modelo e cada meio. MN - Monod, MS - Moser, AW - Andrews e CF - Contois \& Fujimoto

\begin{tabular}{|c|c|c|c|c|c|c|c|c|c|c|c|c|}
\hline & \multicolumn{4}{|c|}{ Meio 1} & \multicolumn{4}{|c|}{ Meio 2} & \multicolumn{4}{|c|}{ Meio 3} \\
\hline & MN & MS & AW & $\mathrm{CF}$ & $\mathrm{MN}$ & MS & AW & $\mathrm{CF}$ & $\mathrm{MN}$ & MS & AW & $\mathrm{CF}$ \\
\hline $\mathrm{K}_{\mathrm{S}}(\mathrm{g} / \mathrm{L})$ & 11,521 & 2,574 & 60,435 & 1,644 & 21,849 & 2,651 & 64,788 & 1,369 & 237,026 & 8,472 & 43,856 & 4,999 \\
\hline$\mu_{\mathrm{m}}\left(\mathrm{h}^{-1}\right)$ & 3 & 0,313 & 3,326 & 0,288 & 1,241 & 0,303 & 3,321 & 0,263 & 7,249 & 472 & 1,500 & 0,338 \\
\hline & & $\mathbf{0 , 0 1 3}$ & $-0,014$ & $\mathbf{0}$, & $-\mathbf{0}$, & $\mathbf{0 , 0 2 0}$ & $-0,015$ & $\mathbf{0 , 0 2 9}$ & -0 & $\mathbf{0 , 0 1 0}$ & $-0,015$ & $\mathbf{0 , 0 1 0}$ \\
\hline $\mathrm{K}_{\mathrm{i}}(\mathrm{g} /$ & - & & 50,004 & & 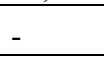 & & 39,198 & - & - & - & 603,678 & - \\
\hline $\mathrm{n}$ & - & 1,836 & - & - & - & 1,615 & - & 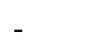 & - & 1,306 & - & - \\
\hline
\end{tabular}

Pela análise da Tabela 2, é possível constatar que foram obtidos valores negativos de coeficiente de manutenção $\left(\mathrm{m}_{\mathrm{s}}\right)$ na maior parte dos casos. Considera-se que esse é um 


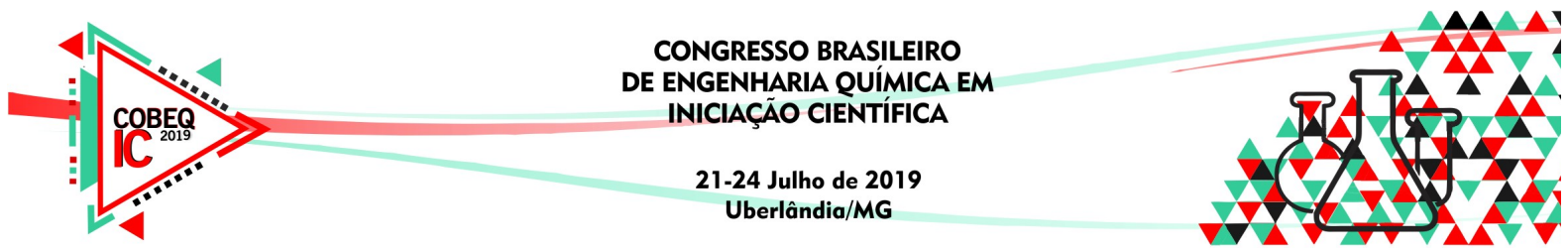

comportamento não usual para bactérias, uma vez que a energia é fornecida pelo meio para que a célula se mantenha viva, isto é, valores positivos de coeficiente de manutenção. Entretanto, este resultado sugere a possibilidade de que este microrganismo possui a capacidade de armazenar energia e utilizá-la para a própria sobrevivência, em etapas de restrição de disponibilidade se substrato, porém, estudos mais aprofundados deverão ser realizados para ratificar esta possibilidade.

Baseado nos resultados obtidos após a simulação e a rotina de estimativa de parâmetros, foi possível calcular os valores do coeficiente de correlação $\left(\mathrm{R}^{2}\right)$ e do desvio relativo médio (DRM) para cada curva de cada modelo. Os dados calculados estão expostos na tabela 3 .

Tabela 3: Desvios relativos médios e coeficientes de correlação calculados para cada modelo analisado e cada meio.

MN - Monod, MS - Moser, AW - Andrews e CF - Contois \& Fujimoto

\begin{tabular}{|c|c|c|c|c|c|c|c|c|c|c|c|c|}
\hline & \multicolumn{4}{|c|}{ Meio 1} & \multicolumn{4}{|c|}{ Meio 2} & \multicolumn{4}{|c|}{ Meio 3} \\
\hline & $\mathrm{R}^{2}$ & $\begin{array}{c}\text { DRM } \\
(\%)\end{array}$ & $\mathrm{R}^{2}$ & $\begin{array}{c}\text { DRM } \\
(\%)\end{array}$ & $\mathrm{R}^{2}$ & $\begin{array}{c}\text { DRM } \\
(\%)\end{array}$ & $\mathrm{R}^{2}$ & $\begin{array}{c}\text { DRM } \\
(\%)\end{array}$ & $\mathrm{R}^{2}$ & $\begin{array}{c}\text { DRM } \\
(\%)\end{array}$ & $\mathrm{R}^{2}$ & $\begin{array}{c}\text { DRM } \\
(\%)\end{array}$ \\
\hline & \multicolumn{2}{|c|}{ Biomassa } & \multicolumn{2}{|c|}{ Substrato } & \multicolumn{2}{|c|}{ Biomassa } & \multicolumn{2}{|c|}{ Substrato } & \multicolumn{2}{|c|}{ Biomassa } & \multicolumn{2}{|c|}{ Substrato } \\
\hline $\mathrm{MN}$ & 0,968 & 15,991 & 0,99 & 6,155 & 0,976 & 16,235 & 0,992 & 7,050 & 0,951 & 25,074 & 0,992 & 4,894 \\
\hline MS & 0,972 & 15,121 & 0,989 & 6,004 & 0,970 & 16,972 & 0,985 & 7,515 & 0,942 & 26,293 & 0,989 & 5,287 \\
\hline AW & 0,976 & 13,437 & 0,996 & 4,119 & 0,979 & 15,544 & 0,991 & 7,422 & 0,939 & 26,555 & 0,992 & 4,457 \\
\hline $\mathrm{CF}$ & 979 & 13,217 & 0,995 & 4,243 & 0,973 & 14,825 & 0,990 & 6 & & 0.713 & 0,990 & 9,186 \\
\hline
\end{tabular}

Por meio da análise dos dados obtidos, foi possível observar que, para os três meios analisados, o modelo de Contois \& Fujimoto, que leva em consideração apenas um substrato como limitante, apresentou os menores desvios relativos médios e os coeficientes de correlação $\left(\mathrm{R}^{2}\right)$ mais próximos a um, Sendo assim, é possível concluir que, para os meios analisados nesta pesquisa e levando em consideração apenas o substrato e a biomassa presente, este modelo é o mais adequado para descrever o processo de fermentação da bactéria Herbaspirillum seropedicae em biorreator em batelada.

\section{CONCLUSÃO}

O software EMSO apresentou uma interface simples e de fácil programação até para sistemas como os tratados neste trabalho, envolvendo equações algébricas e diferenciais acopladas.

O modelo de Contois \& Fujimoto, que leva em consideração apenas um substrato limitante, apresentou resultados com desvio relativo médio (DRM) na faixa de 4 a $9 \%$ para a curva de substrato e 13 a $20 \%$ para curva de biomassa. Além disso, apresentou valores de coeficiente de correlação $\left(\mathrm{R}^{2}\right)$ acima de 0,97 para curva de concentração de substrato e biomassa para todos os meios de cultura estudados.

Foi possível observar a existência de valores de coeficiente de manutenção da célula negativos, o que sugere que este microrganismo possui a capacidade de armazenar energia e utilizá-la para a própria sobrevivência, em etapas de restrição de disponibilidade se substrato. 


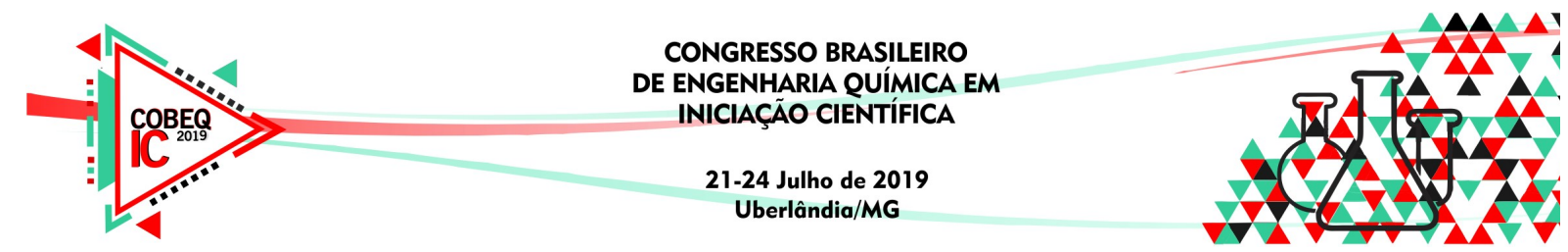

\section{REFERÊNCIAS}

FERREIRA, J, S,; BALDANI, J, I,; BALDANI, V, L, D, Seleção de inoculantes à base de turfa contendo bactérias diazotróficas em variedades de arroz, Acta Scientiarum Agronomy, Maringá, v, 32, n, 1, p, 179-185, 2010.

REIS, V, M,; ALVES, G, C,; MARRIEL, I, E,; REIS JUNIOR, F, B, dos; ZILLI, J, E, Recomendação de inoculante para cultura de milho utilizando a bactéria Herbaspirillum seropedicae, estirpe BR11417 Seropédica: Embrapa Agrobiologia, 2009.

RODRIGUES NETO, J,; MALAVOLTA, J, R, V, A,; VICTOT, O, Meio simples para isolamento e cultivo de Xantomonas campestris pv, Citri Tipo B, Summa Phytopathologica, Piracicaba, v, 12, p, 16, 1986.

SCHEIDT, W, Estratégia de cultivo para produção de biomassa e promotores de crescimento por Herbaspirillum seropedicae BR-11417, Dissertação (Mestrado) Universidade Federal Rural do Rio de Janeiro/UFRRJ, 2015.

SILVA, Sebastião, Plantas forrageiras de A a Z, Viçosa: Ed, Aprenda Fácil, 225p, 2009.

SOARES, R,P,; Manual do Software EMSO, 135 p,; 2007.

BAStián, F., COHEN, A., PICCOLI, P., LUNA, V., BARALDi, R., BOTTINI, R., Production of indole-3-acetic acid and gibberellins A1 and A3 by Acetobacter diazotrophicus and Herbaspirillum seropedicae in chemically-defined culture media. Plant Growth Regul. v. 24, p. 7-11, 1998.

BALDANI, J. I.; BALDANI, V. L. D.; SELDIN, L.; DOBEREINER, J. Characterization of Herbaspirillum seropedicae gen. nov., sp. nov., a root-associated nitrogen-fixing bacterium. International Journal of Systematic Bacteriology, Washington, v. 36, p. 8693, 1986.

Companhia Nacional de Abastecimento (CONAB). Acompanhamento da safra brasileira de grãos. -safra 2012/2013 v.1- Brasília: Conab, 2013 